\title{
HUBUNGAN ANTARA SELF COMPASSION DENGAN ALIENASI PADA SISWA SMA NEGERI 11 PEKANBARU
}

\author{
Riska Juliya Rahayu \\ Fakultas Psikologi, Universitas Islam Riau \\ JI. Kaharuddin Nasution Km. 11 No. 113 Pekanbaru, Indonesia \\ e-mail: Riskajuliyarahayu@gmail.com
}

\begin{abstract}
Student education does not always run smoothly, partly because of the influence of rejection of being excluded from school and peers, rejection leads to alienation. Alienation is a feeling condition in which someone feels not part of anything that no one cares about by staying away from something. This study aims to determine the relation between self compassion and alienation in students senior high school 11 pekanbaru. The research subjects is120 students of senior high school 11 Pekanbaru. The sampling technique in this research was using proportionate stratified random sampling technique. The data collection process uses two scales, the Alienation scale is arranged by haldun (2018) which amounts to 15 items and self compassion scale is arranged by Hasanah and Hidayati (2016) which amounts to 24 items. While the statistical analysis data used in this research is the peason product moment. The result of data analysis showed a correlation coefficient of rxy is $-0,186$ with $p$ is $0,042(p<0,05)$. It can be concluded that there is a negative and significant the relation between Self Compassion and Alienation in students senior high school 11 Pekanbaru. Where the correlation value is negative, it's mean more high self compassion, the more low in students, the opposite more low self compassion, the more high alienation.
\end{abstract}

Keywords: Alienation, education, Self Compassion.

\begin{abstract}
ABSTRAK
Pendidikan para siswa tidak selamanya berjalan mulus salah satunya dikarenakan ada pengaruh penolakan terkucilkan dari lingkungan sekolah dan teman sebaya, penolakan yang menyebabkan munculnya alienasi atau keterasingan. Alienasi suatu kondisi perasaan dimana seseorang merasa tidak menjadi bagian dari apapun bahwa tidak ada orang yang perduli dengan cara menjauhi diri dari sesuatu.Penelitian ini bertujuan untuk mengetahui hubungan antara self compassion dengan Alienasi pada siswa SMA Negeri 11 Pekanbaru.Subjek penelitian ini adalah 120 siswa SMA Negeri 11 Pekanbaru. Teknik pengambilan sampel dalam penelitian ini menggunakan teknik proportionate stratified random sampling. Proses pengumpulan data menggunakan dua skala yaitu, skala Alienasi yang disusun oleh Haldun (2018) yang berjumlah15 aitem dan skala self compassion yang disusun oleh Hasanah dan Hidayati (2016) yang berjumlah 24 aitem. Sedangkan data analisa statistik yang digunakan dalam penelitian ini adalah metode korelasi pearson product moment dimana hasilnya menunjukkan nilai koefisisen korelasi rxy sebesar 0,186 dengan $p$ sebesar $0,042(p<0,05)$. Dapat disimpulkan bahwa adanya hubungan negatif dan signifikan antara self compassion dengan alienasi pada siswa SMA Negeri 11 Pekanbaru, dengan nilai korelasi adalah negatif, artinya maka semakin tinggi self compassion maka semakin rendah alienasi pada siswa, sebaliknya semakin rendah self compassion maka semakin tinggi alienasi pada siswa.
\end{abstract}

Kata Kunci: alienasi, Pendidikan, self compassion. 


\section{PENDAHULUAN}

Pendidikan berkaitan dengan perkembangan dan perubahan perilaku anak didik. Pendidikan juga berhubungan erat dengan pengetahuan, sikap, kepercayaan dan keterampilan serta aspek perilaku lainnya. Pada dasarnya pendidikan adalah proses belajar dan mengajar pola perilaku manusia menurut apa yang diinginkan masyarakat. Pada perkembangan masyarakat yang modern menuntut bahwa sebagian besar tugas pendidikan dijalankan oleh institusi yang disebut sekolah. Sekolah adalah lembaga untuk menambah wawasan dan ilmu pengetahuan, serta penunjang untuk masa depan yang lebih cerah. Sekolah merupakan tempat yang sangat penting untuk menaiki jenjang sosial, melalui sekolah siswa diharapkan bisa memperbaiki masa depan yang baik secara budaya, ekonomi dan kehidupan sosial. Pendidikan disekolah bertujuan untuk menyiapkan peserta didik memasuki masyarakat.

Para siswa yang melakukan pendidikan menengah merupakan pendidikan lanjutan dari sekolah dasar dan sekolah menengah pertama. Pada tingkat sekolah menengah siswa mengalami masa transisi di mulai ketika usia belasan dan berakhir ketika remaja sudah berusia 20 tahun. Hal ini sependapat dengan Papalia dan Olds (dalam Jahja, 2011) yang menyatakan bahwa masa transisi perkembangan antara masa kanak - kanak dan dewasa yang pada umumnya dimulai pada usia 12 atau 13 tahun dan berakhir pada usia akhir belasan tahun atau dua puluhan tahun.

Pendidikan para siswa tidak selamanya berjalan mulus salah satunya dikarenakan ada pengaruh penolakan terkucilkan dari lingkungan sekolah dan teman sebaya, penolakan yang menyebabkan munculnya alienasi atau keterasingan. Hal ini sependapat dengan Hurlock (2004) mengemukakan bahwa remaja lebih rentan terkena alienasi, dikarenakan pada umumnya remaja merasa tidak nyaman dengan standar kelompok secara fisik, sehingga remaja menarik diri serta kepribadian yang melingkupinya adalah kepribadian yang egois, keras kepala, pemurung, dan gelisah yang disebabkan karena belum ditemukannya jati dirinya, sehingga kurang dapat memaknai hidup dengan baik.

Berdasarkan kasus yang terjadi pada hari Senin, 19 Januari 2015 jam 08:29 kasus bunuh diri yang diduga dilakukan arangga (14) seorang pelajar SMP yang tinggal diduga kawasan Pancoran, Jakarta Selatan, membuat perihatin banyak pihak. Pada usia belia, Arangga alias Angga memilih jalan yang tragis dengan mengakhiri hidupnya melalui cara menggantung diri dalam lemari. Hubungan yang tak harmonis dalam keluarga, pertemanan atau lingkungannya, dan juga kebiasaan anak menyerap informasi negatif dari media bisa menjadi beberapa faktor pemicunya. "Anak seperti itu merasa terasingkan, Angga merasa tidak ada yang peduli dengannya, tidak punya teman curhat. Kemudian Angga mendapat pengaruh tidak jelas dari media. Misalnya, dari media dia melihat bahwa ada tempat yang lebih baik dari pada saat ini. Akhirnya Angga memilih cara itu. Angga merasa buat apa lagi hidup ini," kata Kak Seto (tribunnews.com, Kisdiantoro ). Berdasarkan kasus diatas siswa banyak mengalami masalah sehingga siswa yang masih mencari jati dirinya sebagian besar banyak mengambil solusi yang negatif. Hal ini sejalan dengan pendapat Calabrese (dalam Cao, 2016) alienasi memiliki dampak dramatis pada tingkat kepercayaan diri, harga diri, dan pengarahan diri sendiri. Keterasingan tingkat tinggi di kalangan remaja telah ditemukan terkait dengan alkohol dan 
penyalahgunaan narkoba, bunuh diri, masalah perilaku, dan pergaulan bebas seksual.

Siswa yang mengalami alienasi akan memiliki adaptasi yang kurang baik dengan lingkungan, kurang sosialisasi dan tentunya berasal dari teman sebaya yang melilhat seseorang dari segi fisik, warna kulit dan ekonomi. Hal ini sependapat dengan Robson (dalam Sianturi \& Hidayati, 2019) alienasi dapat terjadi dikarenakan adanya perbedaan antar remaja yang dapat memicu penolakan teman sebaya terkait kecatatan fisik, daya tarik fisik, ataupun etnis. Hal ini dikarenakan remaja menilai lingkungan dan teman sebaya berdasarkan keserasian dan kesamaan yang dimilikinya. Henslin (2007) Alienasi yaitu suatu perasaan yang merasa dirinya tidak menjadi bagian dari apapun dan merasa bahwa tidak satu orang pun yang peduli dengan apapun yang terjadi dengan diri kita. Hal ini sependapat dengan Mann (dalam Johnson, 2005) mendefinisikan alienasi sebagai negara atau pengalaman terisolasi dari kelompok atau kegiatan dimana seseorang harus memiliki atau harus terlibat. Karl marx (dalam Wendling, 2008) alienasi (Keterasingan) didefinisikan tidak hanya bahwa diri kodrati menyerahkan diri, mengasingkan dirinya sendiri, tetapi juga bahwa ia menjadi asing bagi dirinya sendiri. Alienasi atau keterasingan adalah suatu kondisi ketika manusia dijauhkan atau menjauhkan diri dari sesuatu, sesama manusia, alam, budaya, tuhan, atau bahkan dirinya sendiri. (Schacht, 2005). Jaeggi (dalam Sianturi \& Hadiyati, 2019) menyatakan bahwa alienasi adalah perasaaan terasing, tidak memiliki kelekatan emosional dengan orang lain sebagai akibat dari ketidakmampuan diri sendiri sehingga individu lebih menutup diri dari lingkungan sosialnya.
Petrovic (dalam Yulianto \& Asih, 2015) menyatakan bahwa alienasi merujuk pada pengertian dasar, seseorang atau sesuatu yang menjadi terasing atau terpisah dari seseorang atau sesuatu lainnya karena suatu tindakan tertentu atau karena akibat dari tindakannya. Sependapat dengan Reveley (dalam Harahap, 2019) mengemukakan alienasi adalah rasa keterasingan yang muncul dalam diri seseorang. Alienasi adalah keadaan subjektif, perasaan menjadi orang asing, seolah-olah seseorang bukanlah diri yang normal. Schabracq dan Cooper (dalam bekhet dkk, 2011). Hal ini sependapat Menurut Chaplin (2000) dalam kamus psikologi, alienasi adalah perasaan keterasingan, rasa terlepas, terpisah, serta ketiadaan rasa hangat atau relasi persahabatan dengan orang lain. Dalam riset yang dilakukan oleh Seeman (dalam Fishman \& Lagnam, 2013) alienasi memiliki beberapa aspek sebagai berikut: Powerlessness (ketidakberdayaan), Meaninglessness (tidak berarti), Social Isolation (terisolasi secara sosial), Normlessness (tidak ada normal) dan Self Estrangement (keterasingan diri)

Kebanyakan siswa sulit untuk mengenali dirinya dengan benar sehingga siswa merasa harus mengasingkan diri dari lingkungan sekitar dan terasingkan oleh temannya sehingga bisa menyebabkan siswa merasa depresi karena merasa terasingkan akan hal ini yang menyebabkan pentingnya peran self compassion terhadap dirinya agar siswa lebih memahami dirinya. Hal ini sependapat dengan Wahyuni dan Arsita (2019) Self Compassion dapat menurunkan berbagai masalah yang dihadapi oleh remaja, seperti tingkat depresi akibat kecenderungan ingin tampil sempurna, alienasi atau perasaan terasing dari orang lain, rasa malu, dan 
perfeksionisme yang memberikan batas pada harapan yang tidak realistis.

Neff (Stevens \& Woodruff, 2018) Self Compassion adalah memberi pemahaman untuk diri sendiri dan mau menerima keadaan dirinya walaupun berada di dalam situasi yang tidak menyenangkan. Hal ini sependapat dengan Neff (2003) Self compassion merupakan keterbukaan dan kesadaran terhadap penderitaan diri, tanpa menghindari penderitaan, memberikan pemahaman dan kebaikan terhadap diri sendiri ketika menghadapi penderitaan, kegagalan dan ketidaksempurnaan tanpa menghakimi diri, serta melihat suatu kejadian sebagai pengalaman yang dialami semua manusia. Neff (2003) menambahkan bahwa self compassion adalah proses pemahaman tanpa kritik terhadap penderitaan, kegagalan atau ketidakmampuan diri dengan cara memahami bahwa ketiga hal tersebut merupakan bagian dari pengalaman sebagai manusia pada umumnya.

Siswa yang merasa dirinya diasingkan oleh teman sebayanya dan lingkungan sosial memiliki sikap yang menutup diri seperti siswa akan memendam perasaan sendiri, maka dari itu self compassion dibutuhkan karena ketika siswa memiliki self compassion yang baik siswa akan bercerita kepada teman dekatnya bahwa dia sedang dalam masalah. Hal ini sependapat dengan Brein dan Chen (2012) yang mengatakan bahwa Self Compassion banyak membantu remaja sebagai seorang individu yang bisa mampu bertahan, memahami dan menyadari makna dari sebuah masalah sebagai hal yang positif berkaitan dengan berbagai aspek seperti aspek kesejahteraan, optimis dan kebahagiaan.

Terkadang kebanyakan siswa yang tidak sayang pada dirinya dikarenakan siswa belum memahami dirinya sendiri. Hal ini berlawanan dengan Breines dan
Chen (2012) mengungkapkan bahwa orang-orang yang menggunakan self compassion dalam menghadapi kelemahan diri memiliki motivasi yang besar untuk meningkatkan dan mengubah perilaku menjadi lebih baik. Siswa mau bersosialisasi dan tidak menyalahkan dirinya sendiri, maka dibutuhkan rasa menyayangi terhadap diri sendiri dan bisa menerima kemampuan yang kita miliki dan tidak merasa rendah diri atau yang dimaksud self compassion agar terhindar dari alienasi. Hal ini sependapat dengan Neff (Stevens dan Woodruff, 2018) mengatakan self compassion merupakan perasaan cinta kasih terhadap diri sendiri dengan perhatian, tidak menghakimi diri sendiri, menerima terhadap pikiran dan pengalaman seseorang. Menurut Menurut Germer (dalam Hidayati 2015), self compassion merupakan kesediaaan diri untuk tersentuh dan terbuka kesadarannya saat mengalami penderitaan dan tidak menghindari penderitaan tersebut.

Neff (2015) Self compassion adalah kemampuan untuk berbelas kasih pada diri sendiri, tanpa kemampuan itu individu mungkin tidak siap untuk berbelas kasih pada orang lain. Hal ini sependapat dengan Neff dan Germer (2018) yang menyatakan bahwa Self Compassion adalah sebuah kemampuan memperlakukan diri sendiri sama seperti memperlakukan seorang teman yang sedang mengalami kesulitan, kegagalan, atau mengalami kehidupan yang berat. Menurut Echols \& Shadily (dalam Adine dkk, 2018) Self compassion sendiri berasal dari kata compassion yang berarti rasa belas kasih, rasa kasih sayang yang dirasakan apabila melihat orang menderita membuat berusaha memahami dan ikut merasakan apa yang ia rasakan, keinginan untuk membantu bukan mengasihani, ada sebuah kebaikan hati, kepedulian, dan memahami. Menurut Neff dan McGehee 
(dalam Azizah, Dkk 2020) Belas kasih diri adalah cara adapatif untuk diterapkan ketika seseorang berada dalam situasi yang sulit. Hal ini sependapat dengan Neff (2003) menjelaskan bahwa self compassion adalah strategi membatasi emosi negatif dengan kesadaran penuh disertai empati.Neff (2003) mengatakan ada 3 aspek pokok self compassion antara lain yaitu : Self Kindness, Common Humanity dan Mindfulness

Berdasarkan uraian permasalahan tersebut, rumusan masalah dalam penelitian ini adalah "Apakah ada Hubungan antara Self Compassion dengan Alienasi di SMA Negeri 11 Pekanbaru?. Tujuan penelitian ini untuk mengetahui Hubungan antara Self Compassion dengan Alienasi di SMA Negeri 11 Pekanbaru.

\section{METODE PENELITIAN}

Populasi dalam penelitian adalah siswa SMA Negeri 11 Pekanbaru dengan jumlah populasi 172. Sampel penelitian yang didapat sebanyak 120 orang dengan tingkat kesalahan pengambilan sampel sebesar $5 \%$ dan teknik yang digunakan adalah Proportionate Sratified Random Sampling. Menurut Sugiyono (2016) Proportionate Sratified Random Sampling adalah teknik pengambilan sampel acak berstata proposional. Teknik yang dilakukan apabila sifat atau unsur dalam populasi tidak homogen dan berstrata secara proposional, sehingga sampel untuk SMA Negeri 11 Pekanbaru peneliti merandom secara acak dari 18 kelas yang terdiri dari kelas $\mathrm{X}$ dan kelas XI. Peneliti mendapatkan empat kelas $X$ dan empat kelas XI. Metode pengumpulan data yang dilakukan penelitian adalah dengan melakukan penyebaran skala. Pada penelitian ini peneliti menggunakan penelitian kuantitatif dengan jenis penelitian korelasi dengan tujuan ingin mengetahui hubungan antara self compassion dengan alienasi pada siswa SMA Negeri 11 Pekanbaru. Penelitian yang digunakan adalah penelitian kuantitatif dan metode yang digunakan adalah metode analisis korelasi product moment.

\section{HASIL DAN PEMBAHASAN}

Tabel 1

Hasil Uji Asumsi Normalitas

One Sample Kolmogrov-Smirnov Test

\begin{tabular}{cccc}
\hline Variabel & $\begin{array}{c}\text { Skor } \\
\text { K-SZ }\end{array}$ & $\boldsymbol{P}$ & Keterangan \\
\hline Alienasi & 0,079 & 0,066 & Normal \\
$\begin{array}{c}\text { Self- } \\
\text { Compassion }\end{array}$ & 0,073 & 0,179 & Normal \\
\hline
\end{tabular}

Berdasarkan hasil uji normalitas menunjukkan pada sebaran data alienasi diperoleh skor sig sebesar 0,066 ( $p>0,05)$, sehingga dapat disimpulkan bahwa sebaran data penelitian Alienasi memperlihatkan distribusi normal. Hasil uji sebaran data self compassion diperoleh skor $p$ sebesar $0,179(p>0,05)$, sehingga dapat disimpulkan sebaran data penelitian menunjukkan distribusi normal, sehingga untuk kedua variabel penelitian memiliki sebaran data yang berdistribusi normal.

\section{Tabel 2}

Hasil Uji Linieritas

\begin{tabular}{lllll}
$\begin{array}{l}\text { Hubunga } \\
\mathbf{n} \\
\text { Variabel }\end{array}$ & $\begin{array}{l}\text { Nilai } \\
\mathbf{F}\end{array}$ & Sig & $\mathbf{P}$ & $\begin{array}{l}\text { Keteran } \\
\text { gan }\end{array}$ \\
& & & & \\
\hline $\begin{array}{l}\text { Hubungan } \\
\text { antara }\end{array}$ & 4.31 & 0.0 & $p<0$, & Linier \\
Self & & 41 & 05 & \\
Compassi & & & & \\
on dan & & & & \\
Alienasi & & & & \\
\hline
\end{tabular}

Berdasarkan pemaparan di atas dapat diketahui bahwa hasil uji linieritas pada kedua variabel yang diteliti menunjukkan bahwa nilai $\mathrm{F}=4,311$ dengan $p=0,041$ $(p<0,05)$, maka dari hasil tersebut dapat disimpulkan bahwa kedua variabel dalam 
penelitian ini memiliki hubungan yang linier.

Tabel 3

Hasil Uji Hipotesis

lations

\begin{tabular}{llrr}
\hline & & Alienasi & \multicolumn{2}{l}{$\begin{array}{l}\text { Self } \\
\text { Compass } \\
\text { ion }\end{array}$} \\
\hline \multirow{4}{*}{ Alienasi } & Pearson & 1 &,$- 186^{*}$ \\
& Correlation & &, 042 \\
& Sig. (2-tailed) & 120 & 120 \\
& $\mathrm{~N}$ &,$- 186^{*}$ & 1 \\
Self & Pearson &, 042 & \\
Compass & Correlation & 120 & 120 \\
ion & Sig. (2-tailed) & $\mathrm{r}$ & \\
\hline
\end{tabular}

Berdasarkan tabel tersebut menunjukkan adanya hubungan yang bersifat negatif dan signifikan antara self compassion dengan alienasi pada siswa SMA Negeri 11 Pekanbaru, dengan adanya hubungan yang negatif maka semakin tinggi self compassion maka semakin rendah alienasi pada siswa, sebaliknya semakin rendah self compassion maka semakin tinggi alienasi pada siswa.

Hasil penelitian yang diperoleh peneliti dapat disimpulkan bahwa self compassion berhubungan erat dengan alienasi. Siswa yang memiliki tingkat self compassion yang tinggi maka siswa akan dapat mengatasi masalah - masalah yang terjadi dalam dirinya. Tetapi sebaliknya ketika self compassion yang rendah maka siswa akan sulit untuk mengatasinya masalah masalah salah satunya seperti ketika siswa merasa diasingkan oleh teman sebaya dan lingkungannya siswa mempunyai resiko saat dewasa akan kesulitan untuk bersosialisasi karena siswa menolak keberadaan orang sekitar. Hal ini sependapat dengan penelitian Robson (2003), mengatakan bahwa individu yang teralienasi dari peer-nya di masa kecil memiliki risiko tinggi terkena simptom depresi dan kesulitan untuk melakukan kegiatan sosial ekonomi di masa dewasa. Kemampuan sosial yang rendah membuat seoorang indvidu akan menolak keberadaan orang lain disekitarnya menyebabkan sulit untuk menjalin hubungan interpersonal.

Siswa yang tidak bisa menerima tekanan dari perasaanya dan tidak bisa menerima pengalamannya dimasa lalu akan merasa dirinya teralienasi. Sebaliknya siswa yang memiliki self compassion yang baik cenderung akan menganggap semua masalah yang ada dalam kehidupannya adalah pengalaman yang harus dilaluinya. Hal ini sependapat dengan Neff (Waring \& Kelly, 2009) belas kasih diri didefinisikan sebagai kecenderungan untuk menanggapi pergulatan pribadi dan perasaan seseorang tentang tekanan dalam menghadapi sesuatu hal dan menyadari bahwa bagian awal dari pengalaman manusia.

Pada dasarnya perasaan terasing baik dari diri maupunlingkungan, akan muncul apabila individu merasa tidak mampu berbuat sesuatu untuk mewujudkan eksistensi dirinya (Paramita dkk, 2012). Hal ini sejalan dengan penelitian Breines dan Chen (2012) mengungkapkan bahwa orang-orang yang menggunakan self compassion dalam menghadapi kelemahan diri memiliki motivasi yang besar untuk meningkatkan dan mengubah perilaku menjadi lebih baik.

Brenner (dalam Tadjuddin, 2012) Seseorang yang mengalami alienasi akan memiliki perasaan merasa kurang memiliki, merasa gelisah, merasa putus hubungan dari keluarga, teman- teman,sekolah atau pekerjaan. Hal ini sependapat dengan Neff dan Germer (2018) yang menyatakan bahwa Self Compassion adalah sebuah kemampuan memperlakukan diri sendiri sama seperti memperlakukan seorang 
teman yang sedang mengalami kesulitan, kegagalan, atau mengalami kehidupan yang berat.

Berdasarkan analisis data kategori self compassion berada pada kategori sedang dengan persentase tertinggi yaitu $36,7 \%$ dapat ditarik kesimpulan bahwa self compassion yang dimiliki oleh siswa SMA Negeri 11 Pekanbaru termasuk kategori sedang. Hal ini menunjukan bahwa sebagian besar siswa memiliki penerimaan yang baik kepada diri sendiri ketika siswa mengalami masalah - masalah yang siswa miliki. Selain itu juga siswa memiliki penerimaan diri yang negatif yang disebabkan oleh ketidakyakinan siswa terhadap potensi yang dimilikinya yang kemudian menjadikan siswa sering mengkritik dirinya sehingga siswa berada dalam masalah itu sendiri. Berdasarkan analisis data data kategori alienasi berada pada kategori sedang dengan presentase tertinggi 35,0\%. Maka dapat ditarik kesimpulan bahwa siswa tidak merasa teralienasi oleh diri sendiri dan teman sebayanya tetapi, siswa merasa teralienasi karena diri sendiri yang tidak ingin terbuka dengan lingkungan sekitarnya sehingga siswa merasa lebih baik sendiri dari pada bersama teman - temannya.

\section{SIMPULAN}

Berdasarkan analisis data dapat disimpulkan bahwa terdapat hubungan negatif yang signifikan antara self compassion dan alienasi. Artinya semakin tinggi self compassion maka semakin rendah alienasi pada siswa, sebaliknya semakin rendah self compassion maka semakin tinggi alienasi pada siswa. Dari hasil penelitian ini peneliti menyadari pada saat menyebarkan skala secara langsung peneliti mengalami kesulitan dikarenakan covid-19 sehingga peneliti hanya bisa menyebarkan skala melalui google form dan ada siswa yang dibagikan skala kemungkinan besar tidak benar-benar serius dalam pengisian skala, karena skala dikirim via online sehingga peneliti berharap kepada para siswa agar dapat menceritakan kepada guru ataupun teman dekat (sahabat) ketika mengalami masalah. Siswa harus lebih terbuka tentang masalah yang dialaminya agar terhindar dari alienasi dan siswa diharapkan dapat mempertahankan dan menaikkan kemampuan self compassion karena self compassion dapat membuat individu untuk mampu bersikap welas asih pada diri atau mencintai diri. Untuk menumbuhkan self compassion pada diri siswa, siswa harus mengenali dirinya terlebih dahulu, menyayangi dirinya dan lebih terbuka dengan teman - teman disekitarnya, curhat kepada guru, teman, dan keluarganya jika siswa mengalami masalah. Kepada guru dan pihak sekolah diharapkan memberikan mata pelajaran BK untuk siswa kelas $\mathrm{X}$ dan $\mathrm{XI}$ untuk sharing dan mendengarkan siswa mengenai permasalahan yang siswa alami baik secara akademik maupun non akademik. Kegiatan ini diharapkan mampu membantu siswa untuk lebih terbuka pada diri, teman sebaya maupun lingkungan,sehingga dapat membantu siswa mengurangi perasaan teralienasi. Untuk peneliti selanjutnya disarankan untuk meneliti variabel - variabel lain yang dapat mempengaruhi alienasi seperti self Improvement, self kindness, dan lain-lain. Dan juga peneliti selanjutnya juga memperluas subjek penelitian yang berbeda seperti pada sekolah menengah pertama, mahasiswa dan lain - lain.

\section{DAFTAR PUSTAKA}

Adine, dkk(2018). Peran Self-Compassion Adine, dkk(2018). Peran SelfCompassion Terhadap Kualitas Hidup Terkait Kesehatan Pada Remaja Miskin 
di Jakarta.Fakultas Psikologi Universitas YARSI

Azizah, dkk (2020). The Effectiveness of Strength Based Intervention Motivational interviewing Group Counseling to Improve Students' Self Compassion. Jurnal Bimbingan Konseling Vol 9 No 2.Universitas Borneo Tarakan, Kalimantan Timur, Indonesia

Bekhet, Dkk. (2011). The Effects of Positive Cognitions on the Relationship between Alienation and Resourcefulness in Nursing Students in Egypt.Issues in Mental Health Nursing

Breines, J. G., \& Chen, S. (2012). Selfcompassion increase self-improvement motivation. Personality and Social Psychology Bulletin, 38(9), 1133-1143. doi:10.1177/0146167212445599

Cao, Gazang. 2016. Alienation of Tibetan Adolescent in rural boarding schools. Research article. Front Education China

Fishman, K \& Langmen.(2010). Alienation.Jurnal Sociopedia Isa.

Haldun, Ibnu (2018) Perbedaan Alienasi Pada Mahasiswa Ditinjau Dari Keikutsertaan Mahasiswa Dalam Berorganisasi. Skripsi.Fakultas Psikologi Universitas Muhammadiyah Malang

Harahap, H. (2019). Pengaruh Alienasi Terhadap Penggunaan Media Sosial.Jurnal Komunikologi Vol 16 No 2. Universitas Esa Unggul

Hidayati, Diana Savitri (2015) self compassion dan loneliness.Jurnal IImiah Psikologi Terapan Vol 3 No. 01. Fakultas Psikologi, Universitas Muhammadiyah Malang

Hurlock. Elizabeth B. 2004. Psikologi Perkembangan. Jakarta : PT. Gelora. Aksara Pratama.

Hasanah \& Hidayati.(2016). Hubungan antara Self Compassion dengan Alienasi pada Remaja.Jurnal Empati Vol 5. Fakultas Psikologi. Universitas Diponegoro

Henslin, J.M. (2007). Sosiologi dalam Pendekatan Membumi (first ed.). Jakarta: Erlangga

Jahja, Yudrik. (2011). Psikologi Perkembangan. Jakarta: Kencana.
Johnson, G. M. (2005). Student alienation, academic achievement, and WebCT use.Vol 8 No.2. Educational Technology \& Society.

Kisdiantoro.(2015, Januari 19). Jabar Tribun News. Diakses dari https://jabar.tribunnews.com/2015/01/19 /pelajar-smp-gantung-diri-karenamerasa-terasingkan

Mahandika, D. F. (2018). Keterasingan manusia menurut Karl Marx...Vol 14. PIMPIN Bandung

Marlina, Leni (2015). Hubungan Antara Motif Berafiliasi Dengan Alienasi Pada Narapidana di Lembaga Pemasyarakatan Pekanbaru. Skripsi thesis. Universitas Islam Negeri Sultan Syarif Kasim Riau

Neff, K. (2003). Self-compassion: An alternative conceptualization of a healthy attitude toward oneself. Self and identity, 2(2), 85-101. Diunduh dari: https://www.tandfonline.com/doi/abs/10. 1080/15298860309032.

Neff, Kristin. (2015). SELF-COMPASSION. Amerika: Epub Edition

Neff, K. D. (2011). Self-compassion. New York: HarperCollins

Neff, \&Germer . (2018). The Mindful SelfCompassion Workbook. New York: The Guilford Press.

Philip, O. (2007). Jangan Terlalu Dekat Narsisus. Jurnal Psikologi 1, 26-28

Robson, K. (2003). Peer alienation: predictors in childhood and outcomes in adulthood. Iser Working Papers, 21, 1$30 . \quad$ diakses dari http://www.iser.essex.ac.uk/pubs/workp aps

Rozaki, A. (2012, Oktober).Bunuh diri di kalangan anak dan remaja Indonesia. The Living and the Dead(12). diunduh dari http://kyotoreview.org/wpcontent/uploads/Bunuh-DiriRemajaIndonesia.pdf

Schacht, R. (2005). Alienasi Pengantar Paling Komprehensif. Jakarta: Jalasutra.

Sianturi \& Hadiyati.(2019). Hubungan antara Self Disclosure dengan Alienasi pada mahasiswa tahun pertama Suku Batak. Jurnal Empati. Vol 8. Universitas diponegoro 
Stevens \& Woodruff. (2018). The Neuroscience of Emphaty, Compassion, and Self Compassion. London: Academic Press

Tadjuddin, Nilawati (2016). Pencegahan Alienasi Pasca Bencana Alam. Prosiding International Seminar \&Workshop Post Traumatic Counseling.STAIN Batusangkar

Waring, S. V., \& Kelly, A. C. (2019). Trait Self-Compassion Predict Different Responses To Failure Depending On
Te Interpersonal Context. Personality and Individual Differences, 143, 47-54.

Doi:https://doi.org/10.1016/j.paid.2019.01.0 43.

Wendling, Amy E. (2009). Karl Marx On Technology and Alienation. New York: Palgrave MacMillan

Yulianto \& Asih.(2015). Alienasi diri pada komunitas Underground ditinjau dari sikap terhadap prasangka sosial.Fakultas Psikologi Universitas Semarang 
Volume 1, No.1, Juni 2021 